\title{
COMPARAÇÃO DE BIOMASSA VEGETAL E ANIMAL EM BIOARGAMASSA
}

\section{VEGETABLE AND ANIMAL BIOMASS COMPARSION IN BIOMORTAR}

\author{
JUPIRA ALMEIDA, M.SC. |UPF \\ ANTONIO THOME, PhD . |UPF \\ FABIANA TONIAL, Dra. |UPF \\ ROBERTO DE CARLI DE MARTINI |UFTPR
}

\begin{abstract}
RESUMO
O uso de microrganismos em meio líquido para o processo de biocimentação, favorece a continuidade do crescimento bacteriano. Entretanto se este demora para ser usado, para de crescer rapidamente, levando a morte celular. Este estudo comparou duas formas de produção de uma biomassa, capaz de armazenar os microrganismos em estado de latência mantendo a viabilidade para posterior utilização. Aqui foi descrito o preparo de biomassas, feitas com materiais orgânicos e bactéria Sporosarcina pasteurii (CCT 0538 ATCC 1185). Foram testadas biomassas de origem animal (esterco de aves) e vegetal (ervilhaca - Vicia villosa Roth). Ambas biomassas mantiveram a viabilidade dos microrganismos, sendo que a vegetal foi mais eficiente apresentando maior crescimento bacteriano após a revitalização. Para teste foram moldados corpos de prova referência (sem biomassa) e também com cada uma delas, e depois de 28 dias ensaiados a tração e compressão. A resistência a tração apresentou um aumento de 41,2 \% (biomassa animal) e de 44,7 \% (biomassa vegetal). Na resistência a compressão o aumento foi de $37,8 \%$ (biomassa animal) e de $38,8 \%$ (biomassa vegetal), comparados a argamassa de referencia (sem adição de microrganismo).
\end{abstract}

PALAVRAS-CHAVE: Biocimentação; Biomineralização; Bioargamassa; Material orgânico; Sporosarcina pasteurii.

\begin{abstract}
The use of microorganisms in liquid medium for the biocementation process, favors the continuity of bacterial growth. However, if it takes too long to use, it stops growing rapidly, leading to cell death. This study compared two forms of biomass production, capable of storing microorganisms in a latent state, maintaining viability for later use. Here we described the preparation of biomasses, made with organic materials and bacteria Sporosarcina pasteurii (CCT 0538 ATCC 1185). Animal (poultry manure) and vegetable (vetch - Vicia villosa Roth) biomasses were tested. Both biomasses maintained the viability of the microorganisms, and the vegetable was more efficient, presenting greater bacterial growth after revitalization. For testing, reference specimens were molded (without biomass) and also with each one of them, and after 28 days tested for traction and compression. The tensile strength showed an increase of 41.2\% (animal biomass) and $44.7 \%$ (plant biomass). In the compressive strength, the increase was $37.8 \%$ (animal biomass) and $38.8 \%$ (vegetable biomass), compared to the reference mortar (without the addition of a microorganism).
\end{abstract}

KEYWORDS: Biocementation; Biomineralization; Bio-mortar; Organic matter; Sporosarcina pasteurii. 


\section{INTRODUÇÃO}

Os materiais aglomerantes utilizados em misturas de argamassa e concreto são geralmente industrializados e concebidos com materiais e recursos de matéria-prima não renováveis, os chamados recursos fósseis. Ambientalmente, são grandes os ônus que a fabricação do cimento proporciona para a natureza, como mostram os dados do Ministério da Ciência, Tecnologia, Inovações e Comunicações (2014), o cimento é o principal responsável por emissões de gás carbônico (CO2) na atmosfera, dentre todos os produtos do setor construtivo nacional.

Existem vários estudos que buscaram o aprofundamento no conhecimento e na técnica da biocimentação para produzir materiais através da utilização de bactérias presentes na natureza. Alguns microrganismos apresentam a capacidade metabólica de se biomineralizar conforme o fornecimento de elementos químicos para esse processo, o qual culmina na formação do carbonato de cálcio, composto que originará a calcita. Voltados para a construção civil, Afifudin et al. (2011), Dhami et al. (2013) e Ivanov (2016) encontraram resultados otimistas, realizando trabalhos com a adição de bactérias capazes de precipitar carbonato de cálcio (CaCO3) nas misturas ou depositando-as em fissuras e patologias de estruturas existentes.

$O$ processo que se denomina biocimentação é oriundo da biomineralização. A biomineralização segundo De Muynck et al. (2010), é o processo de produção de minerais por microrganismos, que pode depender ou não de fatores do ambiente, e pode acontecer de maneira induzida em mistura ou em disposição sobre estruturas existentes, se dividindo então em biodeposição e biocimentação. Segundo De Muynck et al. (2010), a biodeposição consiste na aplicação de produtos biomineralizantes que são lançados a estruturas já existentes. Já a biocimentação, caracteriza-se pelo processo de formação de cristais de calcita em microrganismos, incorporados às misturas de concreto e argamassa ainda no estado fresco, utilizando-se das reações bioquímicas realizadas pelo metabolismo destes microrganismos.

Achal e Mukherjee (2015) esclarecem que a precipitação microbiana de carbonato induzida envolve reações bioquímicas complexas regidas por duas enzimas importantes: a urease e anidrase carbônica, produzidas por microrganismos utilizando ureia como substrato e fonte de cálcio para mineralização. Durante a atividade da urease, $1 \mathrm{~mol}$ de ureia consumida contribui para $1 \mathrm{~mol}$ de amônia e 1 mole de carbamato, conforme apresentado na Equação 1 (BURNE: CHEN, 2000 apud ACHAL: MUKHERJEE, 2015), que espontaneamente hidrolisa para formar um adicional de 1 mol de amônia e ácido carbônico, como mostra a Equação 2 (BURNE: CHEN, 2000 apud ACHAL: MUKHERJEE, 2015), também conhecida como atividade ureolíticas. Esses produtos formam subsequentemente bicarbonato e 2 moles de íons de amônio e hidróxido, apresentados nas Equações 3 e 4 (BURNE: CHEN, 2000 apud ACHAL: MUKHERJEE, 2015), após equilibrar em água que dá origem a um aumento no $\mathrm{pH}$ e, finalmente, deslocar o equilíbrio de bicarbonato, resultando na formação de íons carbonato, definido na Equação 5 (BURNE: CHEN, 2000 apud ACHAL: MUKHERJEE, 2015). Devido ao aumento do $\mathrm{pH}$ na célula, uma alta concentração de íons cálcio extracelular e uma baixa concentração extracelular de prótons são necessárias para a secreção de íons carbonato. Condição de $\mathrm{pH}$ elevado favorece a formação de $\mathrm{CO} 32$ a partir de HCO3- (KNOL, 2003 apud ACHAL: MUKHERJEE, 2015). Finalmente, a concentração de carbonato aumenta induzindo um aumento no nível de supersaturação levando à precipitação de $\mathrm{CaCO} 3$ ao redor da célula na presença de íons de cálcio solúvel, mostrados nas Equações 6 e 7 (KNOL, 2003 apud ACHAL: MUKHERJEE, 2015).

$$
\begin{aligned}
& \mathrm{CO}\left(\mathrm{NH}_{2}\right)_{2}+\mathrm{H}_{2} \mathrm{O} \rightarrow \mathrm{NH}_{2} \mathrm{COOH}+\mathrm{NH}_{3} \\
& \mathrm{NH}_{2} \mathrm{COOH}+\mathrm{H}_{2} \mathrm{O} \rightarrow \mathrm{NH}_{3}+\mathrm{H}_{2} \mathrm{CO}_{3} \\
& \mathrm{H}_{2} \mathrm{CO}_{3} \leftrightarrow \mathrm{HCO}_{3}^{-}+\mathrm{H}^{+} \\
& 2 \mathrm{NH}_{3}+2 \mathrm{H}_{2} \mathrm{O} \leftrightarrow 2 \mathrm{NH}_{4}^{+}+2 \mathrm{OH}^{-} \\
& \mathrm{HCO}_{3}^{-}+\mathrm{H}^{+}+2 \mathrm{NH}_{4}^{+}+2 \mathrm{OH}^{-} \leftrightarrow \mathrm{CO}_{3}^{2-}+2 \mathrm{NH}_{4}^{+}+2 \mathrm{H}_{2} \mathrm{O} \\
& \mathrm{Ca}^{2+}+\text { Cell } \rightarrow \text { Cell }-\mathrm{Ca}^{2+} \\
& \text { Cell }-\mathrm{Ca}^{2+}+\mathrm{CO}_{3}^{2-} \rightarrow \text { Cell }-\mathrm{CaCO}_{3}^{-}
\end{aligned}
$$

Uma das principais dificuldades apontadas nos estudos de biocimentação é a forma de uso dos microrganismos, pois quando em meio líquido, eles devem ser utilizados logo que a concentração desejada seja alcançada, já que o armazenamento por períodos longos inviabiliza seu uso.

Buscando a manutenção da viabilidade de bactérias utilizadas para a realização do processo de biocimentação, faz-se necessário o uso de meios de cultura que mitiguem as condições naturais, como materiais orgânicos. Dessa forma, tanto matéria orgânica vegetal como animal podem suprir as necessidades dos microrganismos. Como exemplos desses substratos temos a ervilhaca e o esterco de aves, que apresentam constituintes importantes para essa finalidade. A ervilhaca tem sido associada como fonte de nitrogênio, fósforo, potássio e magnésio (Acosta et al., 2011 e Ferreira et al., 2014) e o esterco de peru como nitrogênio, fósforo, potássio e enxofre (Santinato et al., 2012). Amaral et al. (2012) constataram melhora na qualidade de mudas de morangueiro utilizando o esterco de peru como substrato. 
A presente pesquisa explorou a viabilidade de armazenamento do microrganismo Sporosarcina pasteurii (CCT 0538 ATCC 11859), bactéria produtora de urease, juntamente a um material orgânico, em forma de biomassa, como forma de garantir a viabilidade de uso posterior, para confecção de argamassassa.

\section{MATERIAIS E MÉTODOS}

O trabalho foi realizado em 4 etapas, como descrito na sequência.

\subsection{Etapa 1 - Produção da solução bacteriana}

A bactéria com potencial de precipitação de carbonato de cálcio para efetivar a biocimentação utilizadas no estudo foi uma cepa de Sporosarcina pasteurii (CCT 0538 ATCC 11859). A partir de colônias mantidas em ágar TSA (Tryptic Soy Agar) com ureia, o microrganismo foi repicado em 10 erlenmeyer (100 mL cada frasco) contido em $1000 \mathrm{~mL}$ de caldo nutriente, o qual foi mantido em mesa agitadora orbital a $497 \mathrm{rpm}$ sob temperatura ambiente, até atingir a absorbância desejada de 0,063 (OD600nm), equivalente a concentração de $1,5 \times 108 \mathrm{UFC} / \mathrm{mL}$. Segundo Achal et al. (2011), Bang et al. (2000), Ramachandran et al. (2001), Ramakrishnan (2007) e Day et al. (2003) esse gênero bacteriano possuem a capacidade de produção da enzima urease, que foi confirmada em laboratório, por ensaio realizado em pesquisa anterior, onde observa-se a alteração da cor parda do meio de cultura TSA (Tryptic Soy Agar) com ureia, para rosa, após o crescimento do microrganismo (Tabela 1).

\begin{tabular}{|c|c|c|c|c|c|c|c|c|c|}
\hline \multirow[b]{3}{*}{$\begin{array}{l}\text { Medidas } \\
(\mathrm{cm})\end{array}$} & \multicolumn{9}{|c|}{ Tempo (horas) } \\
\hline & \multicolumn{3}{|l|}{24} & \multicolumn{3}{|l|}{48} & \multicolumn{3}{|l|}{72} \\
\hline & 1,2 & 2,0 & 2,1 & 8,0 & 8,0 & 8,0 & 8,0 & 8,0 & 8,0 \\
\hline Imagem & & & & & & & & & \\
\hline
\end{tabular}

Tabela 1: Quantificação da urease em ágar ureia de Christensen (do microrganismo Sporosarcina pasteurii- C(T 0538 ATSS 11859).

Fonte: Autores (2020)

Foi possível também verificar a produção de calcita, conforme mostrado na Figura 01, conseguindo uma média de $0,018 \mathrm{~g} / \mathrm{mL}$, seguindo o protocolo de Bhaduri et al. (2016).

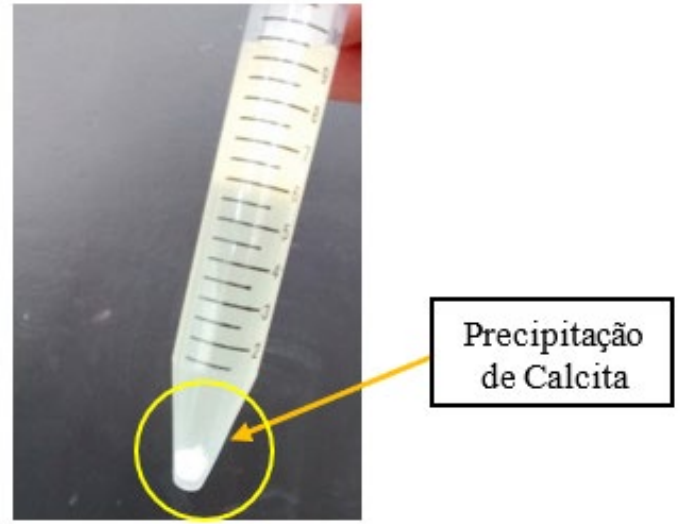

Figura 1: Ensaio de Precipitação de carbonato de cálcio. Fonte: Autores (2020)

O fluxograma da Figura 2 demonstra as etapas realizadas para a produção da suspensão bacteriana utilizada para confeccionar as biomassas.

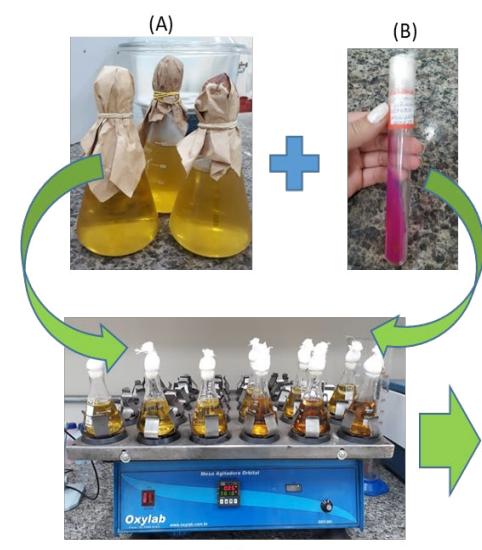

(C)

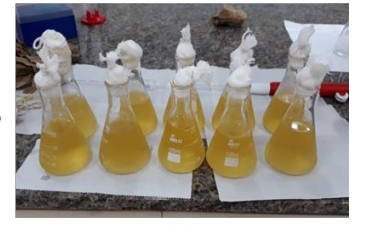

(D)
Figura 2: Produção da suspensão bacteriana. (A) Caldo nutriente; (B) Inóculo bacteriano (Sporosarcina pasteurii-CCT 0538 ATSS 11859); (C) Caldo contaminado com microrganismo, em processo de ativação em mesa agitadora orbital a 497 rpm; (D) Suspensão bacteriana com absorbancia 0D $600 \mathrm{~nm}$ de 0,063 (equivalente a 1,5 × $108 \mathrm{UFC} / \mathrm{mL}$ ). Fonte: Autores (2020)

\subsection{Etapa 2 - Produção da biomassa}

O procedimento utilizado para compor as biomassas foi a coleta de ervilhaca (Vicia villosa Roth), como material orgânico vegetal, procedendo sua secagem em temperatura de $36 \mathrm{C}^{\circ}$ dentro de uma estufa e após foi triturado em triturador mecânico. $O$ material orgânico animal - esterco de Peru - foi adquirido pronto, em loja agropecuária. Para compor a biomassa foi misturado, para cada tipo de material orgânico, $250 \mathrm{~mL}$ da solução bacteriana confeccionada na etapa 1, com 12,5 g do material orgânico seco e a mistura foi posta para secar em temperatura variando entre 26 a $28 \mathrm{C}^{\circ}$ na estufa, revirando-os todos os dias. Após seco, a peso constante, procedeu-se o ensaque e o armazenamento em ambiente natural, protegido do sol e da chuva. 
O fluxograma da Figura 3 apresenta as etapas realizadas para a produção das biomassas com os materiais orgânicos vegetal e animal.

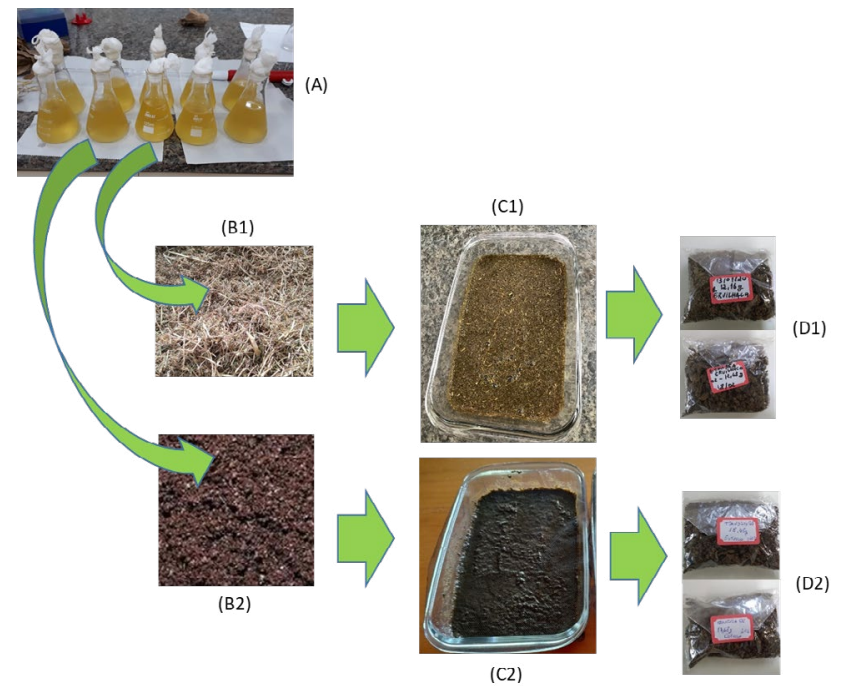

Figura 3: Produção das biomassas. (A) Suspensão bacteriana com absorbância OD $600 \mathrm{~nm}$ (equivalente a 1,5 x 108 UFC/mL); (B1) Material orgânico vegetal: Ervilhaca (Vicia villosa Roth); (C1) Mistura da biomassa com material orgânico vegetal: Ervilhaca (Vicia villosa Roth); (D1) Biomassa com material orgânico vegetal: Ervilhaca (Vicia villosa Roth) - seca e embalada; (B2) Material orgânico animal: Esterco de Peru; (C2) Mistura da biomassa com materia orgânico animal: Esterco de Peru; (D2) Biomassa com material orgânico animal: Esterco de Peru - seco e embalado. Fonte: Autores (2020).

\subsection{Etapa 3 - Revitalização da biomassa e con- tagem bacteriana}

Para testar a eficiência na conservação do microrganismo nos materiais orgânicos, foram contadas as colônias bacteriana nas placas de Petri contendo ágar TSA (Tryptic Soy Agar). Para isso, a biomassa foi revitalizada diluindo-se 15 $\mathrm{g}$ em $350 \mathrm{~mL}$ de água contendo $8 \mathrm{~g}$ de ureia fertilizante $(45 \% \mathrm{~N})$, quantidade suficiente para confeccionar um molde prismático de argamassa. Esta suspensão foi aquecida em banho-maria $\left(28-30^{\circ} \mathrm{C}\right)$ por 3 horas, mexendose a cada 30 minutos. A cada hora $0,1 \mathrm{~mL}$ do conteúdo líquido foi inoculado nas placas e incubadas em estufa a $25^{\circ} \mathrm{C}$ por 48 horas, sendo realizada a contagem das colônias após 24 horas e novamente em 48 horas. A contagem bacteriana foi realizada em triplicata. Ao final das 3 horas o líquido restante foi adicionado aos demais materiais da argamassa, compondo a bioargamassa. Por fim, foram moldados corpos de prova, para serem rompidos aos 28 dias para testar resistências mecânicas à tração na flexão e à compressão axial.

O fluxograma da Figura 4 apresenta as etapas realizadas para a revitalização das biomassas com material orgânico vegetal e animal.

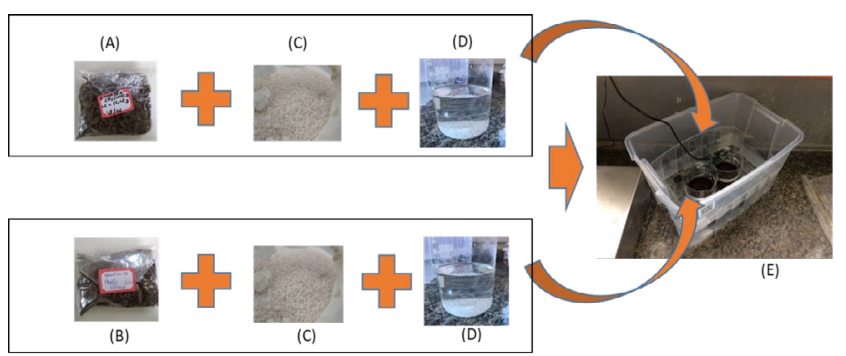

Figura 4: Revitalização das biomassas. (A) Biomassa com material organico vegetal: Ervilhaca (Vicia villosa Roth); (B) Biomassa com material orgânico animal: Esterco de Peru; (C) ureia fertilizante ( $45 \% \mathrm{~N}$ ); (D) água; (E) Biomassa revitalizando em banho-maria.

Fonte: Autores (2020)

O processo de revitalização da biomassa consiste na adição de $15 \mathrm{~g}$ de biomassa (com material organico vegetal e/ou animal), acrescido de $8 \mathrm{~g}$ de ureia fertilizante (45\% N) diluída em $350 \mathrm{~g}$ de água, esta mistura é mantida em banho-maria por 3 horas, em temperatura variando entre $28-30^{\circ} \mathrm{C}$, mexendo a mistura a cada 15 minutos. Após este período a mistura é coada e acrescida aos demais materiais, para compor a bioargamassa.

O fluxograma da Figura 05, mostra o preparo das placas de Petri, para contagem bacteriana.

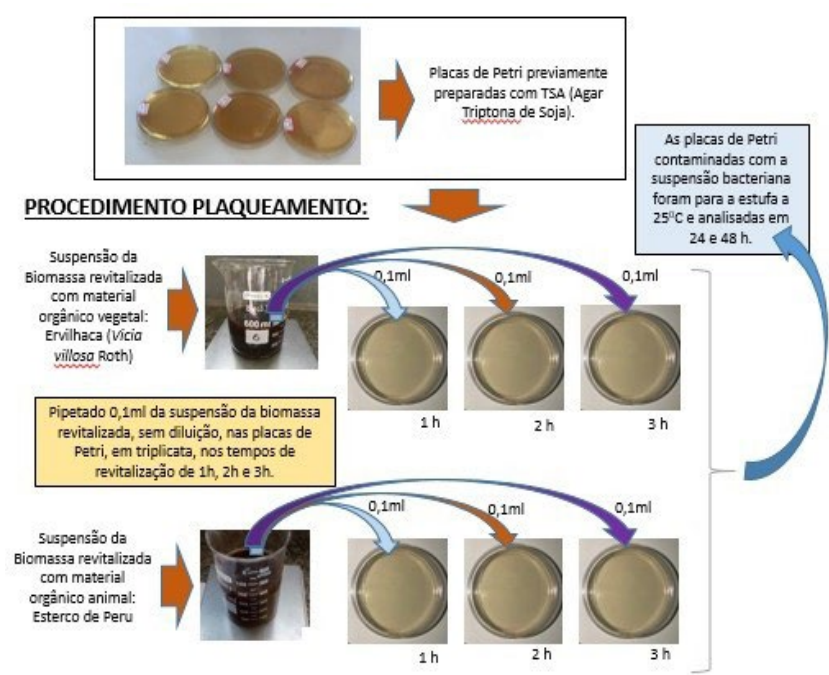

Figura 5: Preparo das placas de Petri para contagem bacteriana.

Fonte: Autores (2020)

\subsection{Etapa 4 - Produção da argamassa e da bioargamassa}

Para testar a eficácia da biomassa, foi realizado a confecção de moldes prismáticos para argamassa com biomassa vegetal (BIOV), argamassa com biomassa animal (BIOA) e argamassa de referência (REF), na qual os materiais são os mesmos, porém não possui a adição de microrganismos, de acordo com a norma técnica ABNT NBR 13279:2005. Os materiais para compor o traço da argamassa $(1: 2: 1,5: 6)$ foram metacaulim, cal hidráulica, calcário calcítico e areia, 
respectivamente, sendo que o calcário calcítico e a cal hidráulica forneceram cálcio ao meio metabólico, para os moldes com microrganismo. Os materiais orgânicos, animal e vegetal, utilizados para compor as biomassas foram o esterco de aves de peru e a ervilhaca, respectivamente.

\section{RESULTADOS E DISCUSSÕES}

\subsection{Contagem bacteriana}

Nas amostras com material orgânico animal, foi possível fazer uma estimativa de colônias nos períodos estimados (Figura 6 e Tabela 2). Nas amostras oriundas de material orgânico vegetal não foi possível realizar a contagem devido ao intenso crescimento das colônias nos períodos estimados (Figura 7). Com isso, observou-se que ambos os materiais são satisfatórios para a manutenção da viabilidade dos microrganismos testados.

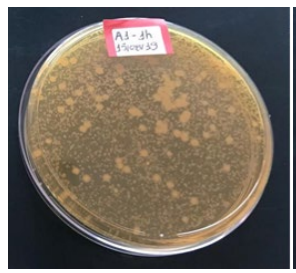

1 hora de revitalização

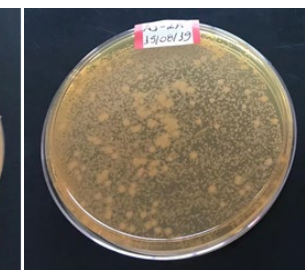

2 horas de revitalização

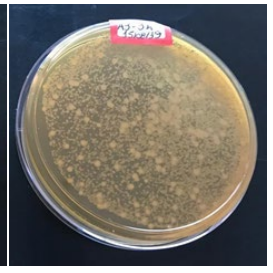

3 horas de revitalização
Figura 6: Placas de Petri contendo microrganismos armazenados em material orgânico animal (Esterco de Peru).

Fonte: Autores (2020)

A tabela 2 apresenta a contagem de colônias que cresceram nas placas da figura 6, em material orgânico animal.

\begin{tabular}{|l|l|l|l|l|l|l|}
\hline Amostra & Leitura & $\begin{array}{l}\text { Tempo de } \\
\text { Revitali- } \\
\text { zação }\end{array}$ & $\begin{array}{l}\text { Qtd. } \\
\text { média }\end{array}$ & $\begin{array}{l}\text { 1ml } \\
\text { (UFC/ml) }\end{array}$ & $\begin{array}{l}350 \mathrm{ml} \\
(\mathrm{UFC} / \mathrm{ml})\end{array}$ & UFC/g \\
\hline A1 & $\begin{array}{l}24 \\
\text { horas }\end{array}$ & 1 hora & 2012 & 20120 & 7042000 & $4,7 \mathrm{E}+05$ \\
\hline A2 & $\begin{array}{l}24 \\
\text { horas }\end{array}$ & 2 horas & 2239,33 & 22393,33 & 7838667 & $5,2 \mathrm{E}+05$ \\
\hline A3 & $\begin{array}{l}24 \\
\text { horas }\end{array}$ & 3 horas & 2354,00 & 23540 & 8239000 & $5,5 \mathrm{E}+05$ \\
\hline Amostra & $\begin{array}{l}\text { Leitura } \\
\text { Revitali- } \\
\text { zação }\end{array}$ & $\begin{array}{l}\text { média } \\
\text { (UFC/ml) }\end{array}$ & $\begin{array}{l}\text { (UFC/ml) } \\
\text { Aempo de }\end{array}$ & UFC/g \\
\hline A1 & $\begin{array}{l}48 \\
\text { horas }\end{array}$ & 1 hora & 2498 & 24980 & 8743000 & $5,8 \mathrm{E}+05$ \\
\hline A2 & $\begin{array}{l}48 \\
\text { horas }\end{array}$ & 2 horas & 2317,33 & 23173,33 & $8,111 \mathrm{E}+06$ & $5,4 \mathrm{E}+05$ \\
\hline A3 & $\begin{array}{l}48 \\
\text { horas }\end{array}$ & 3 horas & 2579 & 25790 & 9026500 & $6,0 \mathrm{E}+05$ \\
\hline
\end{tabular}

Tabela 2 - Contagem bacteriana dos microrganismos armazenados em material orgânico animal (Esterco de Peru).

Fonte: Autores (2020)
Observa-se que nos períodos de incubação de 24 e 48 horas a biomassa manteve em torno 105 UFC viáveis, evidenciando que o material orgânico foi eficaz na conservação dos 108 UFC viáveis adicionados a ele.

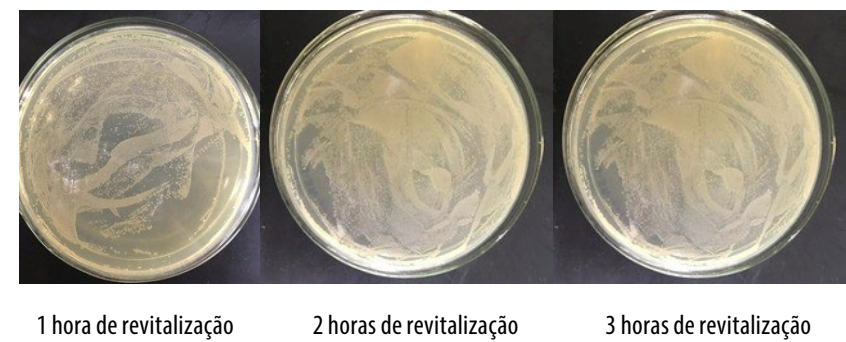

Figura 7: Placas de Petri contendo microrganismos armazenados em material orgânico vegetal (Ervilhaca - Vicia villosa Ruth).

Fonte: Autores (2020)

Ao tentar realizar a contagem de microrganismos nas placas contendo biomassa vegetal (Figura 7), verificou-se um grande crescimento de colônias, o que impossibilitou a contagem das mesmas, como feito na biomassa animal (figura 6), indicando um melhor desempenho de armazenamento de bactérias.

\subsection{Produção da argamassa e da bioargamassa}

Os corpos de prova foram moldados como argamassa de referência (REF), de bioargamassa contendo a suspensão bacteriana revitalizada sob material orgânico animal (BIOA) e de bioargamassa contendo a suspensão bacteriana de material orgânico vegetal (BIOV). Após 28 dias da moldagem das amostras, as mesmas foram ensaiadas quanto à resistência mecânica à tração e à compressão, no traço 1:2:1,5:6 (metacaulim: cal hidráulica: calcário calcítico: areia). Os resultados são representados no gráfico da Figura 8.

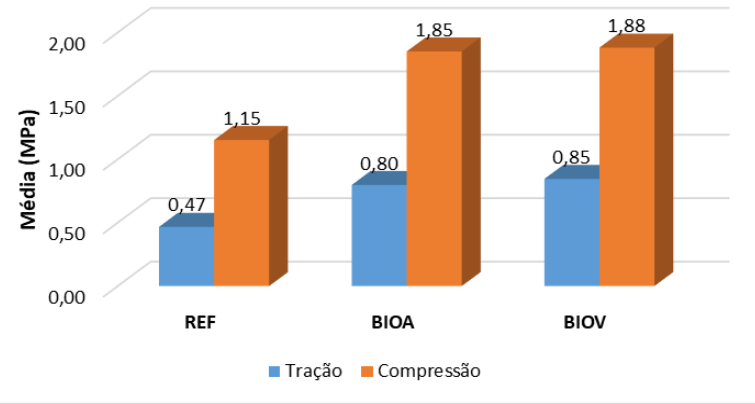

Figura 8: Resistência mecânica dos corpos de prova.

Fonte: Autores (2020)

A partir dos resultados da Figura 8, percebe-se que as resistências à tração e a compressão, em ambos os traços que continham suspensão bacteriana com materiais 
orgânicos, apresentaram desempenho superior que o traço de referência (sem adição de microrganismo). Os dois materiais orgânicos, tanto animal como vegetal, apresentaram boas condições de armazenamento da Sporosarcina pasteurii, com destaque para o material orgânico vegetal, a ervilhaca (Vicia villosa Roth), que teve um crescimento maior quando da revitalização, e consequentemente, um melhor desempenho nas resistências mecânicas dos corpos de prova analisados, sendo 5,9 \% na tração e 1,6 \% na compressão, mais resistentes que o material orgânico animal, o esterco de Peru. Comparando os resultados entre as amostras de bioargamassa e a amostra de argamassa de referência, as bioargamassa obtiveram um desempenho maior na resistência a tração de 41,2 \% (biomassa animal) e de $44,7 \%$ (biomassa vegetal) e, na resistência a compressão o aumento foi de $37,8 \%$ (biomassa animal) e de $38,8 \%$ (biomassa vegetal), comprovando a eficácia do mecanismo microbiano na precipitação de carbonato de cálcio com posterior biocimentação.

\section{CONSIDERAÇÕES FINAIS}

O objetivo do trabalho foi verificar a viabilidade de armazenamento do microrganismo Sporosarcina pasteurii (CCT 0538 ATCC 11859), bactéria produtora de urease, em materiais orgânicos, vegetal e animal, e se os mesmos eram capazes de suprir as necessidades de sobrevivência das bactérias. Isto foi demonstrado pela superioridade dos valores de resistência mecânica à tração e a compressão dos materiais em relação ao traço de argamassa sem a adição de microrganismo, definido como referência (REF).

A ervilhaca (Vicia villosa Roth) mostrou-se um substrato de secagem mais rápida do que o material orgânico animal, fator este que favorece a etapa de produção. Se realizar análise estatística entre os valores obtidos na contagem das colônias das duas biomassas (vegetal e animal) as diferenças seriam imperceptíveis, desta forma os dois materiais orgânicos são capazes de armazenarem os microrganismos e garantir sua sobrevivencia quando revitalizados.

Este estudo é complementar ao projeto de pesquisa de produção de argamassas de assentamento e revestimentos utilizando a técnica da biocimentação, em andamento, no qual carece ainda de análises mais aprofundada das propriedades da argamassa nos estados fresco e endurecido, objeto de próximos artigos, assim como, investigações da microestrutura utilizando microscópio eletrônico de varredura (MEV), Difração de Raio X (DRX) e Fluorescência de Raio X (FRX) das amostras secas, para comprovação do aumento do teor de calcita, pela adição de microrganismos.

\section{REFERÊNCIAS}

ACHAL, Varenyam; MUKERJEE, Abhijeet. A review of microbial Precipitation for sustainable construction. Construction and Building Materials. Vol. 93, may 2015, pg. 1224-1235. doi.org/10.1016/j. conbuildmat.2015.04.051. Disponível em: <https://www.sciencedirect.com/science/article/pii/ S0950061815005000>. Acesso em: 24 jun. 2016.

AFIFUDIN, H. et al. (2011). Microbial participation in the formation of calcium silicate hydrated (CSH) from bacillus subtilis. Paper presented at the Procedia Engineering, , 20 159-165. doi:10.1016/j. proeng.2011.11.151

ASSOCIAÇÃO BRASILEIRA DE NORMAS TÉCNICAS. 13279: Argamassa para assentamento e revestimento de paredes e tetos - Determinação da resistência à tração na flexão e à compressão. 1 ed. Rio de Janeiro: Moderna, 2005.

BHADURI, Swayamdipta; DEBNATH, Nandini; MITRA, Sushanta; LIU, Yang; KUMAR, Aloke. Precipitação de calcite induzida microbiologicamente mediada por Sporosarcina pasteurii. Journal of Visualized Experiments. 2016; (110): 53253. Doi: 10.3791/53253. Disponível em <https://www.ncbi.nlm.nih.gov/pubmed/27167458>. Acesso em: s03 set. 2019.

BANG, Sookie S.; GALINAT, Johnna K.; RAMAKRISHNAN, V.. Calcite precipitation induced by polyurethane-immobilized Bacillus pasteurii. Enzyme And Microbial Technology, Rapid City, v. 28, n. 2, p.402-409, 17 out. 2000. Disponível em:

<www.elsevier.com/locate/enzmictec >. Acesso em: 17 out. 2000.

COSTA, João José Soares. Biotecnologia e Biomimetismo: Contributos Inovadores para a Ecoeficiência da Indústria da Construção. Dissertação de mestrado em Engenharia Civil. Universidade do Minho. Braga, Portugal, 2014. Disponível em:

<http://repositorium.sdum.uminho.pt/handle/1822/36246>, acesso em: 22 fev. 2016.

DE MUYNCK, Willem; DE BELIE, Nele; VERSTRAETE, Willy. Microbial carbonate precipitation in construction materials: A review. Eccological Engineering 36, pg. 118-136. Belgium, 2010.

DHAMI, N. K. et al. (2013). Viability of calcifying bacterial formulations in fly ash for applications in building materials. Journal of Industrial Microbiology and Biotechnology, 40(12), 1403-1413. doi:10.1007/ s10295-013-1338-7 
FERREIRA, Paulo Ademar Avelar et al. Biomass decomposition and nutrient release from black oat and hairy vetch residues deposited in a vineyard. Revista Brasileira de Ciência do Solo, Bento Gonçalves, v. 1, n. 38, p. 1621-1632, fev. 2014.

IVANOV, V. K. et al. (2016). Using extraction and sorption processes to obtain nanosized powders of calcium silicates and functional materials on their basis. Theoretical Foundations of Chemical Engineering, 50(4), 490-497. doi:10.1134/ S0040579516040023. Disponível em: <https:// www- scopus.ez116.periodicos.capes.gov.br/record/ display.uri?eid=2s2.084986220550\&origin=resultslist $\&$ sort $=$ plff $\&$ src $=s \&$ sid $=f d 200608 c d 79 d f c 37 a-$ abd282690d7d2c\&sot=autdocs\&sdt=autdocs\&s$\mathrm{I}=18 \& \mathrm{~s}=$ AUID\%2856532555100\%29\&relpos=64\&citeCnt $=0$ \&searchTerm $=>$

MCIP (org.). Ministério da Ciência, Tecnologia, Inovações e Comunicações. 2014. Disponível em: $<$ https://antigo.mctic.gov.br/mctic/opencms/institucional/paginalnstitucional.html>.

Acesso em: 02 fev. 2014.>

RAMAKRISHNAN, V.. Performance characteristics of bacterial concrete - A smart biomaterial. Anais da $1^{\text {a }}$ Conferência Internacional sobre Recentes Avanços na Tecnologia do Concreto, RAC 2007, Páginas 67-78. $1^{\text {a }}$ Conferência Internacional sobre Avanços Recentes na Tecnologia do Concreto, RAC 2007; Sheraton em Crystal City Washington; Estados Unidos; 19 a 21 de setembro de 2007; Código 111076. Disponível em:<https://www.tib.eu/en/search/id/tema\%3ATEMA20080507849/Performance- characteristics-of-bacterial-concrete/>. Acesso em: 28 abr. 2018.

SANTINATO, R. et al. Doses de esterco de peru na substituição parcial - proporcional das adubações NPKS mineral na produção do cafeeiro. In: CONGRESSO BRASILEIRO DE PESQUISAS CAFEEIRAS, 38., 2012, Caxambu. Anais... Brasília, DF: Embrapa Café, 2012. (1 CD-ROM), 2p. <https://www.sciencedirect.com/science/article/pii/S0950061815005000>. Acesso em: 24 jun. 2016.

\section{AUTORES}

ORCID iD: https://orcid.org/0000-0003-2085-2289

JUPIRA ALMEIDA, M.Sc. | Universidade de Passo Fundo. PPGEng | Passo Fundo, RS - Brasil | Correspondência para: Rua Eugenio Felini, 767 - Tapejara - RS, 99950-000| jupira. almeida@live.com

ORCID iD: https://orcid.org/0000-0002-1247-7434

ANTONIO ThOMÉ, PhD.|Universidade de Passo Fundo. PPGEng | Passo Fundo, RS - Brasil | Correspondência para: Rodovia BR-285, Km 171 - Passo Fundo - RS, 99052-900 | thome@ upf.br

ORCID iD: https://orcid.org/0000-0001-7884-3591

FABIANA TONIAL, Dra. I Universidade de Passo Fundo. PPGAgro | Passo Fundo, RS - Brasil | Correspondência para: Rodovia BR-285, Km 171 - Passo Fundo - RS, 99052900 | fabianatonial@upf.br

ORCID iD: https://orcid.org/0000-0003-2138-4595 ROBERTO DE CARLI DE MARTINI | Universidade tecnológica federal do Paraná. PPGEC | Pato Branco, PR - Brasil | Correspondência para: Travessa Sta Rita, 46 - Constantina - RS, 99680-000 | martinir@alunos.utfpr.edu.br

\section{COMO CITAR ESTE ARTIGO}

ALMEIDA, Jupira; THOMÉ, Antonio; TONIAL, Fabiana; MARTINI, Roberto de Carli de. Comparação De Biomassa Vegetal E Animal Em Bioargamassa. MIX Sustentável, [S.I.], v. 7, n. 4, p. 31-38, set. 2021. ISSN 24473073. Disponível em:<http://www.nexos.ufsc. br/index.php/mixsustentavel>. Acesso em: dia mês. ano. doi:https://doi.org/10.29183/2447-3073.MIX2021. v7.n4.31-38.

DATA DE ENVI0: 06/05/2021

DATA DE ACEITE: 07/05/2021 
